\title{
CrimRxiv
}

\section{REPORTED CRIME IN MAP COMMUNITIES COMPARED WITH OTHER NYC AREAS}

John Jay Research and Evaluation Center

Published on: Jun 25, 2020

DOI: 10.21428/cb6ab371.a2cb7a0b

License: Creative Commons Attribution 4.0 International License(CC-BY 4.0). 
